Scientific Journal Warsaw University of Life Sciences - SGGW

Problems of World Agriculture volume 19 (XXXIV), number 1, 2019: 47-58

DOI: 10.22630/PRS.2019.19.1.4

\author{
Mariusz Hamulczuk ${ }^{1}$, Oksana Makarchuk ${ }^{2}$, Edgardo Sica $^{3}$ \\ ${ }^{1}$ Warsaw University of Life Sciences - SGGW, Poland \\ ${ }^{2}$ National University of Life and Environmental Sciences of Ukraine - NULES of Ukraine \\ ${ }^{3}$ University of Foggia, Italy
}

\title{
Price Behaviour and Market Integration: Preliminary Evidence from the Ukrainian and European Union Rapeseed Markets
}

\begin{abstract}
This paper aims to provide preliminary evidence about the existence of horizontal integration between the rapeseed markets in Ukraine (UA) and the European Union (EU). To this end, both a trade analysis and a price analysis were carried out. In particular, the trade analysis was performed using yearly trade flows between the UA and EU, whereas price co-movement was assessed by means of linear vector error correction model (VECM) applied to weekly prices for rapeseed from 2008 to 2018. Our findings provide evidence of strong integration between the UA and EU markets in terms of the trade of rapeseeds, rape cake, and rape oil, as well as high horizontal rapeseed price transmission between the two economies.
\end{abstract}

Key words: price behavior, horizontal market integration, Ukraine, European Union, rapeseed market

JEL Classification: F1, F6, Q1, C5

\section{Introduction}

World agricultural commodity prices have undergone large fluctuations since 2006, often characterized by extreme upward and downward movements, which have provoked political disturbance in many economies (Bellemare 2014). Various factors have driven such turbulences, including changes in supply and demand, financial issues, political regulations, oil prices fluctuations, and the demand for feedstock for biofuel production (OECD-FAO, 2017; Vãduda, 2016). Among factors underlying the increase of market volatility in the last decade a temporal decrease of spatial market integration is mentioned. Indeed, in the case of a lack of spatial integration, no optimal allocation of resources would take place, as producers and consumers would make decisions based on incomplete market signals. Moreover, without horizontal integration of markets, price signals will not be transmitted from deficit to surplus regions and producers will not specialize according to comparative advantage.

In this framework, the present paper aims to answer the question of whether the Ukrainian (UA) and European Union (EU) rapeseed markets are horizontally integrated and if so, what is the nature of this integration. The rapeseed market was taken into consideration in this study because we could not find any studies related to the integration of the UA rapeseed market with foreign markets. The growing importance of the biofuel market in the EU is a factor that also justifies our choice. Rapeseed imported to the EU is

\footnotetext{
${ }^{1} \mathrm{PhD}$, Nowoursynowska 166 Str, 00-278 Warsaw, Poland, e-mail: mariusz_hamulczuk@sggw.pl; https://orcid.org/0000-0002-4956-8516

${ }^{2} \mathrm{PhD}$, e-mail: makarchukoks@gmail.com; https://orcid.org/0000-0002-5997-5879

${ }^{3}$ PhD, e-mail: edgardo.sica@unifg.it; https://orcid.org/0000-0001-9054-8309
} 
processed for rape oil and/or for biodiesel to fulfill the requirements of biofuel production, strengthening integration of UA and EU rapeseed markets.

In order to investigate the extent to which the UA and EU rapeseed markets are integrated, we first conducted a trade analysis on the basis of yearly rapeseed, rapeseed oil, and rapeseed crush balance sheets. Then, we investigated price linkages between the UA and EU rapeseed markets by employing linear vector error correction models (VECMs) on weekly price data. The price transmission between markets is often interpreted as providing insights into their infrastructure efficiency and transaction costs (Hernández-Villafuerte, 2011).

The paper is organized as follows: Section 2 presents the main literature on market integration, spatial arbitrage, and the law of one price (LOP); Section 3 discusses the data and methods of empirical investigation; Section 4 reports the results obtained; finally, Section 5 ends with some concluding remarks.

\section{Theoretical framework}

Horizontal market integration can be defined in various ways. Most definitions refer to the extent to which the agricultural commodity market in a country responds to shocks in another market. The theory of market integration and spatial price transmission is founded on spatial arbitrage, according to which when the difference in a product's price in two markets is higher than the trade costs, arbitrages would occur along with profit-making opportunities (Djuric et al., 2015). Trade flows from surplus regions to deficit regions lead to increase of prices in the exporting market and to decrease of prices in the importing market.

Following Fackler and Goodwin (2001, p. 978), in this paper we define market integration in terms of expectation of the following price transmission ratio:

$$
R_{A B}=\frac{\partial p_{B} / \partial \varepsilon_{A}}{\partial p_{A} / \partial \varepsilon_{A}}
$$

where $\partial p_{B}$ represents the change in the product's price in region $\mathrm{B}, \partial p_{A}$ the change in the product's price in region $\mathrm{A}$, and $\varepsilon_{A}$ is a price shock that affects the product's demand only in region A. Consequently, markets $\mathrm{A}$ and $\mathrm{B}$ will be completely integrated if $R_{A B}=1$.

In this framework, the LOP can be considered as a consequence of spatial arbitrage. In a seminal work, Isard (1977) defined the LOP as an indicator of an efficient market in which a good must have only one price, assuming the absence of transportation costs or trade restrictions. In other words, it implies that the price of a commodity is the same in all locations and that no opportunity exists for spatial arbitrage behavior. The LOP is generally proposed in strong and weak versions. The first assumes that price transmission occurs immediately and that there are no differences in price across markets. The second version considers markets for a good as being integrated when there is a long-run relationship among the prices of that good, and allows for price disparities between markets (Goychuk and Meyers, 2011; Kulikov, 2014).

Horizontal market integration may be investigated using a variety of data and concepts. Therefore a few alternative concepts of market integration appear in the literature. Three basic information sources are used in empirical tests: information about prices in analyzed regions, information about trade flows as well as information about trade costs 
and trade barriers. Inference can take place based on only one type of information or on several at once. We can test only the existence of integration (and its character) or we can analyse the changes in the strength of such integration.

According to Barrett and Li (2002), a sufficient condition for spatial market integration is a trade flow. Tradability refers to the possibility of the physical sale of a given commodity in another market. If trade is taking place, then markets can be considered as integrated, which is basic proof of linking these markets. The higher the trade, the higher the market integration. In addition, Ravallion (1986) interpreted market integration as spatial locations connected by trade, which is reflected in price links.

Transaction costs and trade barriers are key information used in assessment of market integration processes. Transaction costs create a wedge for transmission of shocks between regions. Generally, the higher transaction costs and trade barriers are, the lower the propensity to trade (Anderson and van Wincoop, 2004). Due to lack of detailed information about transaction costs (especially for monthly and weekly frequencies), in most analyses such information is omitted. Instead, some analyses of market integration are based on investigation of absolute price differences (see for example Gluschenko, 2010). Decrease of absolute price differences between regions over time is regarded as an indicator of so-called sigma convergence, and thus an increase in the of strength of market integration. It is worth mentioning, however, that in some cases the price differences could be lower than transaction costs, and the sigma-convergence analysis may lead to misleading conclusions about horizontal market integration.

The vast research in horizontal agricultural market integration is based solely on price series and price transmission models. Therefore, most definitions of market integration refer to the co-movements of prices and, more generally, to the smooth transmission of price signals and information across spatially separate markets (Hernández-Villafuerte 2010). Harriss (1979) explained that the integrated markets are characterized by intermarket price correlations. In addition, Goodwin and Schroeder (1991) considered market integration to occur when locations experience one-for-one price changes. Amikuzuno (2010) defined spatial market integration as a measure of the degree to which markets at geographically separate locations share common long-run price or trade information on a homogenous commodity. Jamora and Cramon-Taubadel (2017) define market integration as the process by which price differences among various locations or related goods tend to be nonexistent or follow similar patterns over a long period.

Listorti and Esposti (2012) present a review of concepts and time series methods used in spatial price transmission. The basis for empirical framework for horizontal price transmission assumes that prices in one country are a function of prices in another region and transaction costs. The main obstacle in the price market integration analyses is the lack of information about transaction costs. Therefore, this term and related parameters are usually skipped. Instead, constant and trend are included as proxy for transaction costs and their changes. The lack of a true transaction costs variable leads to problems with estimating long run-relationships, underestimation of price transmission ratio (especially adjustment to the long-run equilibrium relationship) and makes it difficult to know the real mechanisms in transmission of price shock (nonlinear adjustment). To capture the relationships between prices, the literature has identified three aspects of price transmission analysis that lie within the extremes of strong market integration and the absence of such integration (Djuric et al., 2015; Listorti, 2009; McNew, 1996). The first is the magnitude of price adjustments (i.e. the price transmission ratio), that defines the extent to which price shocks are transmitted from 
one market to another. In particular, the full transmission of price shocks indicates strong market integration whereas no transmission suggests the lack of any market integration. The second is the speed of adjustment, which represents the speed (time lag) at which price shocks are transmitted from a market to another. Finally, the last element of price transmission is the asymmetry of price adjustments, given by the differences in price adjustments depending on whether the price shocks are positive or negative. The extension of the spatial price analyses might cover also other nonlinear price adjustments.

\section{Data and methods}

To analyze the integration of the UA and EU rapeseed markets, we used two types of data. In particular, the first part of our empirical research was based on yearly rapeseed, rapeseed oil, and rapeseed crush balance sheets for the UA and the EU taken from the United States Department of Agriculture and the Comtrade (USDA Market and Trade Data 2018; UN Comtrade Database 2018). Such data allowed us to examine the production, domestic use and international trade of the above-mentioned commodities with a specific focus on the trade flows between the UA and the EU. Our findings were supplemented with monthly data according to Eurostat showing exports of rapeseed from the UA to EU. This part of the research refers to the tradability concept of horizontal market integration.

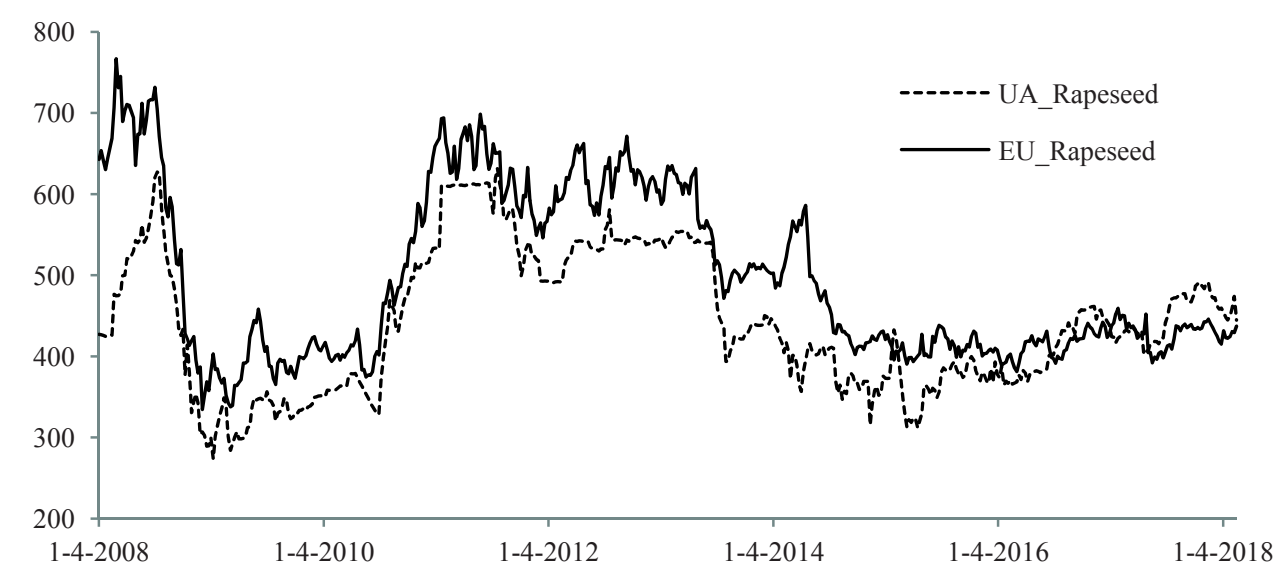

Fig. 1. Weekly UA and EU price series (USD/ton)

Source: Based on OPEC data and APK-Inform.

The second part of our study consisted of an analysis of the price linkages between the UA and EU rapeseed markets. Related literature highlights the importance of employing high-frequency data for price transmission and market integration analysis for improving empirical evidence. Amikuzuno (2010), for instance, showed how most empirical studies on spatial price transmission in agricultural markets fail to use data of relevant frequency for their analyses. Lutz et al. (1994) proved that the time series data of lower frequencies are limited in capturing the relevant market dynamics occurring in the wide interval between one observation and the next. Moreover, the speed of price adjustments toward equilibrium as a consequence of market shocks can be more precisely estimated using high- 
-frequency data than low-frequency data. For this reason, we investigated price integration by using weekly price series for UA (nearby future contract Euronext) and EU rapeseed (ex-work prices) from January 2008 to February 2018. The source of data was the APKInform (2018). The price series are depicted in Figure 1 which shows how UA rapeseed prices follow closely their EU counterparts, suggesting that significant linkages may exist between prices.

In order to implement the price analysis, we first investigated the statistical properties of price series by using the modified Augmented Dickey-Fuller unit root test (ADF-GLS) and Phillips-Peron test (PP), and then we tested for cointegration. In particular, nonstationary time series are cointegrated if their linear combination is stationary $\mathrm{I}(0)$. To this end, we employed a Johansen cointegration framework which is based on the vector autoregressive model (VAR) consisting of the regression of every non-lagged variable on all lagged variables (Tsay, 2010):

$$
\boldsymbol{y}_{t}=\mu_{t}+\boldsymbol{\Phi}_{1} \boldsymbol{y}_{t-1}+\ldots+\boldsymbol{\Phi}_{p} \boldsymbol{y}_{t-p}+\boldsymbol{e}_{t}
$$

where $\boldsymbol{y}_{t}$ represents the stochastic processes collected in $\mathrm{n} \times 1$ vector, $\mu_{t}$ the deterministic variables vector, $\boldsymbol{\Phi}_{i}$ the $(\mathrm{n} \times \mathrm{n})$ coefficient matrices, $p$ the order of the VAR, and $\boldsymbol{e}_{t}$ the unobservable error term. The cointegrating relation appears evident when the VAR is transformed into the vector error correction model (VECM):

$$
\boldsymbol{y}_{t}=\mu_{t}+\boldsymbol{y}_{t-1}+\boldsymbol{\Phi}_{1}^{*} \Delta \boldsymbol{y}_{t-1}+\ldots+\boldsymbol{\Phi}_{p}^{*} \Delta \boldsymbol{y}_{t-p}+\boldsymbol{e}_{t}
$$

where $\Pi=\boldsymbol{\alpha} \boldsymbol{\beta}^{\prime}=\boldsymbol{\Phi}_{\boldsymbol{p}}-\boldsymbol{\Phi}_{\boldsymbol{p - 1}}+\cdots+\boldsymbol{\Phi}_{\mathbf{1}}-\boldsymbol{I}, \boldsymbol{\Phi}_{j}^{*}=\sum_{i=j+1}^{p} \boldsymbol{\Phi}_{i}$ and $\mathrm{j}=1, \ldots, \mathrm{p}-1$. $\boldsymbol{\Pi}$ is the long-run impact matrix and consists of the matrix of cointegration vectors $\boldsymbol{\beta}$ as well as the matrix of adjustments to long run equilibrium $\boldsymbol{\alpha}$ whereas $\boldsymbol{\Phi}_{\mathrm{p}}$ are the short-run impact matrices. Because the rank of long-run impact matrix $\boldsymbol{\Pi}$ gives the number of cointegrating relationships in $\boldsymbol{y}_{t}$, Johansen procedures were used to formulate likelihood ratio (LR) statistics for the number of cointegrating relationships. Two sequential Johansen procedures used to test for the number $m$ of cointegrating relationships are as follows:

$$
\begin{gathered}
\operatorname{LR}_{\text {trace }}(m)=-(T-p) \sum_{i=m+1}^{k} \mathrm{n}\left(1-\hat{\lambda}_{i}\right) \text { and } \\
\operatorname{LR}_{\text {Max }}(m)=-(T-p) \ln \left(1-\hat{\lambda}_{m+1}\right),
\end{gathered}
$$

where $T_{\text {race }}$ is the trace statistic, $L_{\text {max }}$ is the maximum eigenvalue statistic, $T$ is the sample size, and $\hat{\lambda}_{i}$ is the i-th largest canonical correlation (eigenvalues of matrix $\Pi$ ). The trace test tested the null hypothesis of $m$ cointegrating vectors against the alternative hypothesis of $n$ cointegrating vectors. The maximum eigenvalue test tested the null hypothesis of $\mathrm{m}$ cointegrating vectors against the alternative hypothesis of $\mathrm{m}+1$ cointegrating vectors.

After confirming cointegration relationship, a VECM model was estimated (eq. 3). Causal relationship among variables was summarized with impulse response functions (IRF) analysis, variance error decomposition (VED) and Granger causality testing based on the F-statistic (Lütkepohl and Krätzig, 2007). 


\section{Results}

\section{1) Trade analysis}

Data from the USDA-FAS show that the rapeseed production in UA in $2017 / 18$ increased nearly twofold compared to 2016/2017, amounting to 2.2 million (mln) tons. In the same year, the self-sufficiency ratio for rapeseed was 3.8 times higher than in $2005 / 06$, signifying a quite limited domestic consumption.

Moreover, nearly $90 \%$ of rapeseed exports are exported worldwide, e.g. to the EU-28 $53 \%$ and to the Eurasian Economic Union 45\% (i.e., Russia, Belarus, Kazakhstan, Kyrgyzstan, and Armenia) (Tsybulska 2017), suggesting a high direct integration of the UA rapeseed market with the EU and world markets in terms of trade flows. At the same time, the USDA-FAS data about rape oil and rape cake show that most rape oil production is exported (mainly to the EU) and, similarly, that the rape cake production depends on the demand for rape oil and is mostly oriented toward exports; for example, in 2017/2018, the share of exports in total production was $72 \%$. In 2015/16, the EU share of UA rape cake exports in production was $69 \%$. As a result of the low domestic consumption of rape cake, the self-sufficient ratios each year remain high, suggesting a high indirect integration of the UA rapeseed market with global markets.

Turning our analysis to the EU rapeseed, rape oil, and rape cake markets, the USDAFAS data show that domestic consumption of rapeseed in $2017 / 2018$ was $16 \%$ higher than its production. Meanwhile, since $2008 / 09$, more than $10 \%$ of its domestic use has come from imports. An increasing trend can be observed in the rape oil production that was higher than $10 \mathrm{mln}$ tones since 2013/14 MY. Industrial consumption of rape oil in the EU in 2017/18 MY was $7 \mathrm{mln}$ tones, twofold that in 2005/06 MY. The share of the industrial use of rape oil compared with its total production quantity amounted to $61 \%$ in $2005 / 06$ MY, $72 \%$ in $2011 / 12$ MY, and $67 \%$ in $2017 / 18$. The self-sufficiency ratio in the two last periods was stable at 1.02. Based on the EU Biofuels Annual Report in 2017, rape oil for industrial purposes was totally used for biodiesel production (Flach et. all. 2017). Finally, data suggest a yearly growing tendency of rape cake production that correlates to the growing processing of rapeseed. Almost all rape cake was consumed inside the EU. The self-sufficient ratio of rape cake amounted to approximately one point each year, suggesting that its demand is covered by domestic supply.

The EU imports of rapeseed, rape oil, and rape cake from the UA are reported in Figure 2, where UA shares of the total EU import amounts were $31 \%, 39 \%$, and $23 \%$ accordingly. From the Figure, EU rapeseed imports from the UA rapidly increased in 2008, mainly due to the increased demand for biofuel. At the same time, the relevance of rape oil and rape cake import is quite limited compared with rapeseed imports. Overall, therefore, Figure 2 seems to provide some evidence in favor of the trade integration between the rapeseed markets in the UA and EU, mainly via flows of rapeseeds. We call it a direct integration channel expressing the flow of commodity from a surplus region to a deficit region. It is worth noting that rape oil and rape cake imports have fluctuated over time, although they have been increasing starting from 2011, showing the growing importance of indirect channels of UA and EU rapeseed market integration. However, looking at the share of exports to the EU in total UA exports and production, and at the share of imports from the UA in total EU imports and consumption, it is possible to suppose that the UA market is more integrated with the EU market and not the opposite. 


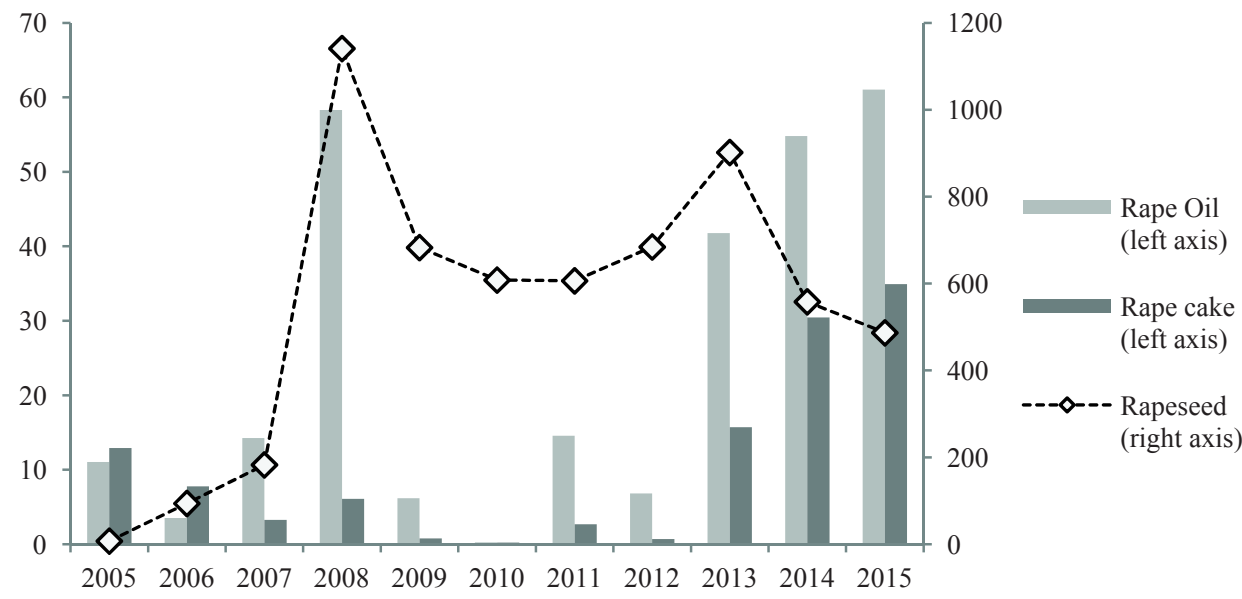

Fig. 2. EU import of rapeseed, rape oil, and rape cake from the UA (mln USD)

Source: Based on the Comtrade database.

To go deeply into the tradability concept of market integration, we have utilized monthly data showing rapeseed trade volume between the UA and EU from January 2008 to February 2018. According to the data, the export of rapeseed from the EU countries to Ukraine was negligible and consisted of only $0.20 \%$ of the export from the UA to EU. Therefore, in Figure 3, only the export from UA to EU was presented.

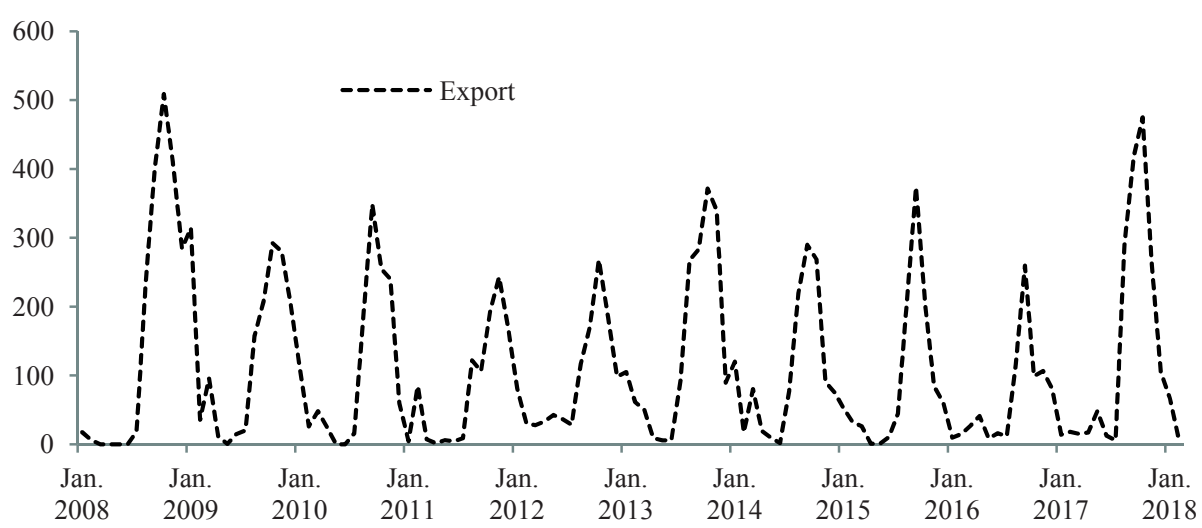

Fig. 3. Monthly export of rapeseed from UA to EU-28 (in 1000 tons)

Source: Based on Eurostat data.

Figure 3 clearly shows that a flow of supply and demand shocks is seasonal in its nature. The rapeseed trade volume observed from August to December is five time higher than the volume in January-July periods. The highest seasonality coefficients (multiplicative model) are for September and October: 2.62 and 2.45 respectively. The lowest are in April-June (below 0.20). Such regularities result from the seasonal character of rapeseed production and the limited possibilities for storing it in Ukraine. 


\section{M. Hamulczuk, O. Makarchuk, E. Sica}

\section{2) Price analysis}

The second part of the research was devoted to linkage of rapeseed prices in the EU and Ukraine. From the unit root tests in weekly price series, the null hypothesis was not rejected in the ADF-GLS and P-P tests at a 5\% significance level for all price series levels, excluding the UA rapeseed. In contrast, the null unit root hypothesis was rejected for the first differences of the price series, suggesting that all price series are integrated of first order $(\mathrm{I}(1))$. In the next step, we therefore tested for cointegration between two series (i.e. UA and EU and rapeseed prices), whose results are presented in Table 1.

Table 1. Cointegration testing results

\begin{tabular}{l|rrrrrrrrr}
\hline \multirow{2}{*}{ Test } & \multicolumn{4}{c}{ Rank } & \multicolumn{2}{c}{ No const. } & \multicolumn{2}{c}{ Restricted const. } & \multicolumn{2}{c}{ Unrestricted const. } & \multicolumn{2}{c}{$\begin{array}{c}\text { Unrestricted trend, } \\
\text { restricted const. }\end{array}$} \\
& & Stat. & p-value & Stat. & p-value & Stat. & p-value & Stat. & p-value \\
\hline LR & 0 & 16.621 & 0.008 & 20.146 & 0.050 & 19.675 & 0.010 & 27.098 & 0.033 \\
trace & 1 & 0.146 & 0.772 & 3.643 & 0.479 & 3.529 & 0.060 & 3.540 & 0.801 \\
& 0 & 16.475 & 0.005 & 16.503 & 0.038 & 16.146 & 0.023 & 23.558 & 0.009 \\
Lmax & 1 & 0.146 & 0.762 & 3.643 & 0.478 & 3.529 & 0.060 & 3.540 & 0.803 \\
\hline
\end{tabular}

Source: Authors' own calculations.

According to the AIC criterion, the number of lags in all VECMs amounted to 4. Evidence of cointegration slightly depends on the specifications of models, (no constant, constant, trend; deterministic components restricted or unrestricted). Generally, in most of models, one cointegration rank can be assumed. The significance of deterministic components suggests that the most suitable model is with unrestricted trends and restricted constants. The time variable in a long run relationship is statistically significant, and the mentioned model has the lowest information criteria values (AIC, HQC) among all compared models. Also, data (Fig. 1) shows a decrease in the gap between prices over the analyzed period, which justifies including time variable in long-run relationship. The estimated VECM with restricted trend and unrestricted constant is presented in Table 2.

Table 2. VECM for UA and EU rapeseed prices

\begin{tabular}{|c|c|c|c|c|c|c|}
\hline \multirow{2}{*}{$\begin{array}{c}\text { Dependent variable } \\
\text { Statistics }\end{array}$} & \multicolumn{3}{|c|}{ d_1_UA_Rapeseed } & \multicolumn{3}{|c|}{ d_1_EU_Rapeseed } \\
\hline & coeficient & t-Statistic & p-value & coefficient & $\mathrm{t}$-Statistic & $\mathrm{p}$-value \\
\hline Constant & -0.025 & -4.206 & 0.000 & 0.008 & 1.271 & 0.204 \\
\hline d_1_UA_Rapeseed_1 & 0.039 & 0.877 & 0.381 & 0.028 & 0.617 & 0.538 \\
\hline d_1_UA_Rapeseed_2 & -0.028 & -0.640 & 0.523 & -0.039 & -0.880 & 0.379 \\
\hline d_1_UA_Rapeseed_3 & 0.030 & 0.707 & 0.480 & -0.026 & -0.595 & 0.552 \\
\hline d_1_EU_Rapeseed_1 & 0.173 & 3.842 & 0.000 & 0.041 & 0.895 & 0.371 \\
\hline d_1_EU_Rapeseed_2 & 0.138 & 3.040 & 0.003 & 0.004 & 0.091 & 0.927 \\
\hline d_1_EU_Rapeseed_3 & 0.099 & 2.167 & 0.031 & 0.070 & 1.501 & 0.134 \\
\hline $\mathrm{EC}$ & -0.070 & -4.396 & 0.000 & 0.023 & 1.410 & 0.159 \\
\hline Lon & relationship & 1_UA_Rap & $-1.021 * 1$ & Rapeseed-0. & $4 *$ time & \\
\hline
\end{tabular}

Source: Authors' own calculations. 
The coefficient in the long-run relationship is 1.02 , providing evidence that a $1 \%$ increase/decrease in EU prices in the long term is reflected in a 1.02\% increase/decrease in the UA prices. Coefficients that were very close to 1 were obtained also from other VECM models. This strongly confirms the UA and EU market integration in the analyzed time frames. Price transmission between the EU and UA markets is very fast. After four weeks, following the $1 \%$ increase of the EU prices, the UA prices rise by $0.71 \%$ (see IRF Fig. 4 ). The response of the EU rapeseed prices for $1 \%$ shock in the UA prices in the same period is less than $0.05 \%$. Moreover, the disequilibrium resulting from shocks in the price system is corrected in one week by $7 \%$ via the response of the UA and by $2 \%$ via the response of EU prices. Since the only significant coefficient with deviations from the long-term equilibrium (EC) appears in the equation for the UA prices, we deducted that the EU market is exogenous for the UA. This is a confirmation of asymmetric integration of the UA and EU rapeseed markets visualized by direction of trade flows.

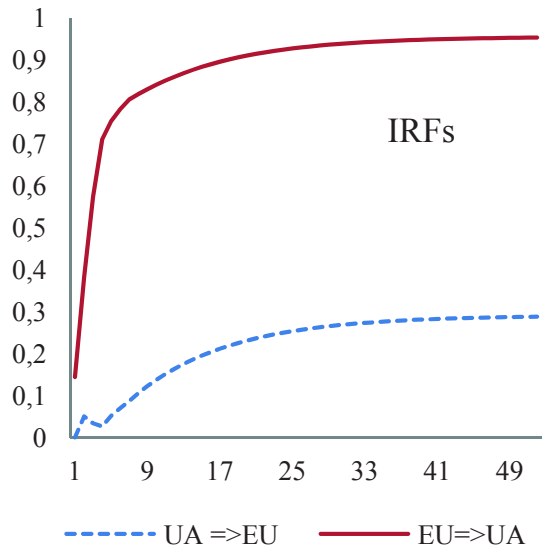

Fig. 4. Impulse response functions (IRFs) for UA and EU rapeseed prices

Source: Authors'own calculations.

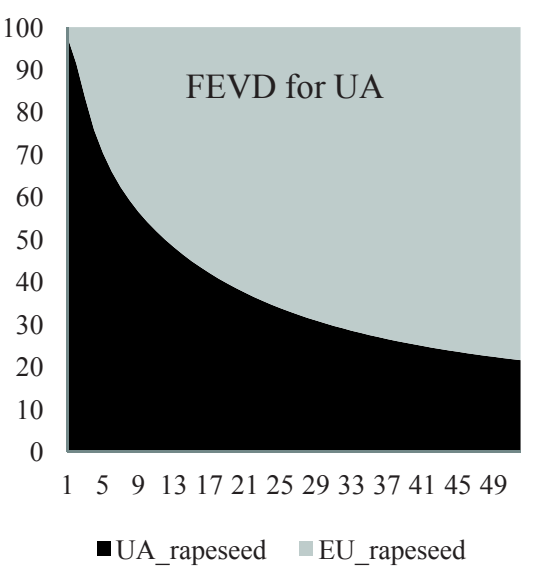

Fig. 5. Forecast error variance decomposition (FEVD) for Ukrainian rapeseed prices

Source: Authors' own calculations.

Performed Granger-causality tests confirm that EU prices are leading UA prices. The null hypothesis stating that EU rapeseed prices are not a Granger-cause for the UA rapeseed prices was rejected $(\mathrm{F}=16.10, \mathrm{p}<0.01)$. The opposite null was not rejected $(\mathrm{F}=0.40, \mathrm{p}=0.82)$. The role of European Union in determining Ukrainian rapeseed prices appears to be clear in Figure 5, which portrays forecast error variance decomposition (FEVD), i.e. the amount of information each variable contributes to the other variables in the VECM. According to the model, in the first 12 weeks after a shock has taken place, domestic (UA) causes overcome EU factors. In contrast, after such a time horizon, international factors (EU market) drive UA rapeseed prices more than domestic factors. 


\section{Conclusions and policy implications}

Despite the fact that the literature stresses the importance of market integration, empirical results about the strength of linkages across markets are inconclusive, varying according to the analyzed markets, data and methods used, and time periods investigated. In this framework, the present paper has explored empirically the linkages between the UA and EU rapeseed markets by following both a trade and a price analysis approach. The main findings achieved can be summarized as follows.

According to the trade analysis, the two markets are integrated due to the trade flow of rapeseed, rape oil and rape cake. More specifically, a significant and seasonal linkage occurs between the UA and the EU rapeseed markets, with the EU importing such an unprocessed commodity mainly for biofuel production. Such an integration is confirmed by the price analysis which provides empirical evidence about the existence of strong linkages between the markets according to the LOP, due to a long-run relationship occurring between the UA and EU rapeseed prices. In particular, the VECM suggests that UA rapeseed prices respond to the EU rapeseed prices and that the price transmission is particularly fast since a $1 \%$ increase in EU prices causes UA prices to raise to $0.71 \%$ within only four weeks. Additionally, a $1 \%$ increase/decrease in EU prices leads to a $1 \%$ increase/decrease in UA prices in the long-run. Furthermore, Granger-causality test and variance error decomposition for UA rapeseed prices indicate that the variance of UA rapeseed prices could be attributed mainly to the shocks in the EU rapeseed prices.

Overall, therefore, our results suggest that the UA acts as a price-taker in the rapeseed market and that the price level is transmitted from global to local agricommodity prices, whereas the opposite effect is quite limited. In other words, policy-makers should opportunely take into account the fact that changes in the EU agricultural policy can significantly affect the UA economy. In this framework, it is worth mentioning that the EU biofuel political framework has triggered a number of linkages between rapeseed and rape oil markets with the biofuel market. In November 2016, the EU Commission published a new legislative proposal for a Renewable Energy Directive (called "RED II") for the period 2021-2030. The goal of RED II is to ensure that the EU will produce at least $27 \%$ of its energy from renewable sources by 2030 . In addition, the RED II sets a cap on conventional biofuels starting from $7 \%$ in 2021 and dropping gradually to $3.8 \%$ in 2030 . It also establishes a mandate on fuel suppliers, requiring them to blend $6.8 \%$ of advanced fuels by 2030. Furthermore, this directive extends the existing biomass sustainability criteria for biofuels (Renewable Energy Directive 2009/28/EC; Directive EU 2015/1513). In the EU, the blending of biodiesel in transport fuels in 2016 was only $5.8 \%$ - well below the $10 \%$ target for 2020. In light of the renewable energy policy about limiting the use of traditional biofuels after 2020, the market conditions thus appear to be oriented toward an upcoming decreased demand for this type of food-based biofuels. Considering our empirical findings, such a policy direction could therefore indirectly reduce the demand for rapeseed and rape oil in the UA market. However, internal factors could also have an effect on UA rapeseed production and the interdependence of prices between local and global markets. A relevant example is a discussion in Ukraine about not reimbursing VAT since 1 March 2018.

The above-mentioned policy changes could produce a twofold outcome for the UA agribusiness. On the one hand, they may lead to decreased domestic rapeseed prices and farm incomes as a result of overproduction and higher transaction costs. On the other hand, 
such a policy could foster domestic processing of rapeseed for oil, making UA and EU rapeseed prices more independent.

\section{Literature}

Amikuzuno, J. (2010). Spatial Price Transmission Analysis in Agricultural Markets: Does the Data Frequency Improve our Estimation? Contributed Paper presented at the Joint 3rd AAAE and 48th AEASA Conference, Cape Town, South Africa, September 19-23.

Anderson J.E., van Wincoop, E. (2004). Trade Costs. Journal of Economic Literature, 42(3), 691-751.

APK inform. (2018). Available at: https://www.apk-inform.com/en/prices.

Barrett C., Li, J. (2002). Distinguishing between Equilibrium and Integration in Spatial Price Analysis. American Journal of Agricultural Economics, 84(2), 292-307.

Bellemare, M. (2014). Rising Food Prices, Food Price Volatility, and Political Unrest. Available at: https://www.cgdev.org/doc/events/WD\%20Food\%20Riots\%20Submission.pdf.

Directive (EU) 2015/1513 of the European Parliament and of the Council of 9 September 2015. Available at: http://eur-lex.europa.eu/legal-content/EN/TXT/?uri=CELEX\%3A32015L1513.

Directive 2009/28/EC of the European Parliament and of the Council of 23 April 2009. Available at: https:/eurlex.europa.eu/legal-content/EN/ALL/?uri=celex\%3A32009L0028.

Djuric, I., Götz, L., Svanidze,M., Levkovych, I., Wolz, A., Glauben, T. (2015). Deliverable 4.2: Agricultural market integration of the Commonwealth of Independent States, 82.

Elliott, G., Rothenberg, T.J, Stock, J. (1996). Efficient Tests for an Autoregressive Unit Root. Econometrica, 64(4), 813-836

Fackler, P.L., Goodwin, B.K. (2001). Spatial Price Analysis. In: B. L. Gardner, and G. C. Rausser (eds.) Handbook of Agricultural Economics, Elsevier, 1 (Part B), 971-1024.

Flach, B., Lieberz, S., Rossetti, A. (2017). EU Biofuels Annual Report 2017. Available at: https:/gain.fas.usda.gov/ Recent\%20GAIN\%20Publications/Biofuels\%20Annual_The\%20Hague_EU28 6-19-2017.pdf

Gluschenko, K., (2010), Price convergence and market integration in Russia. William Davidson Institute Working Paper Number 999, September 2010, 1-44.

Goodwin, B.K., Schroeder, T.C. (1991). Cointegration Tests and Spatial Price Linkages in Regional Cattle Markets. American Journal of Agricultural Economics, 73, 452-464.

Goychuk, K., Meyers, W.H. (2011). Black Sea Wheat Market Integration with the International Wheat Markets: Some Evidence from Co-integration Analysis. Selected Paper Prepared for Presentation at the Agricultural \& Applied Economics Association's 2011, AAEA \& NAREA Joint Annual Meeting, Pittsburgh, Pennsylvania, July 24-26, 2011.

Harriss, B. (1979). There is Method in My Madness: Or Is It Vice Versa? Food Research Institute Studies, 17(2), 197-218.

Hernández-Villafuerte, K. (2011). Relationship between spatial price transmission and geographical distance in Brazil. Paper prepared for presentation at the EAAE 2011 Congress Change and Uncertainty Challenges for Agriculture, Food and Natural Resources, Zurich, Switzerland, August 30 - September 2, 2011.

Isard, P. (1977). How far can we push the law of one price? The American Economic Review, 67(5), 942-948.

Jamora, N., Cramon-Taubadel, S. (2017). What World Price? Applied Economic Perspectives and Policy, 39(3), 479-498. https://doi.org/10.1093/aepp/ppw028

Kulikov, D. (2014). Law of One Price in the euro area: an empirical investigation using Nielsen disaggregated price data. Eestu Pank. Working Paper Series 10/2014: 32.

Listorti, G. (2009). Testing International Price Transmission under Policy Intervention. An Application to the Soft Wheat Market. Associazione Alessandro Bartola. PhD Studies Series 6: 153.

Listorti, G., Esposti, R. (2012). Horizontal Price Transmission in Agricultural Markets: Fundamental Concepts and Open Empirical Issues. Bio-based and Applied Economics, 1(1), 81-96.

Lütkepohl, H., Krätzig, M. (2007). Applied Time Series Econometrics. Cambridge University Press. New York.

Lutz, C., Tilburg, A., Kamp, B. (1994). The Process of Short- and Long-term Price Integration in the Benin Maize Markets. European Review of Agricultural Economics, 22, 191-212.

McNew, K. (1996). Spatial Market Integration: Definition, Theory, and Evidence. Agriculture and Resource Economics Review, Northeastern Agricultural and Resource Economics Association 25(1), 11.

OECD-FAO. (2017). OECD-FAO Agricultural Outlook 2017-2026. OECD Publishing, Paris. Available at: http://dx.doi.org/10.1787/agr_outlook-2017-en. 
Phillips, P.C.B., Perron, P. (1988). Testing for a Unit Root in Time Series Regression. Biometrika, 75(2), 335-346 doi:10.1093/biomet/75.2.335.

Ravallion M., (1986). Testing Market Integration. American Journal of Agricultural Economics, 68(1), 102-109.

Tsay, R.S. (2010). Analysis of Financial Time Series. A Wiley-Interscience Publication John Wiley \& Sons, Inc.

Tsybulska, S. (2017). Реалії ринку олійних культур України (Reality of oilseed market in Ukraine). Prorozitsiya. May 12. Available at: http://propozitsiya.com/ua/realiyi-rynku-oliynyh-kultur-ukrayiny

Ukrstat - Statistical data of the State Statistics Service of Ukraine 2018. Available at: http://www.ukrstat.gov.ua.

UN Comtrade Database 2018. Available at: https://comtrade.un.org/data/.

USDA Market and Trade Data. 2018. Available at: https://www.usda.gov/.

Vãduda, S. (2016). Between Globalization and Integration. The Europeanization of Romania. SpringerBriefs in Economics.

\section{For citation:}

Hamulczuk M., Makarchuk O., Sica E. (2019). Price Behaviour and Market Integration: Preliminary Evidence from the Ukrainian and European Union Rapeseed Markets. Problems of World Agriculture, 19(1), 47-58; DOI: 10.22630/PRS.2019.19.1.4 